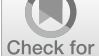

Check for

updates

Cite as

Nano-Micro Lett.

(2021) 13:44

Received: 18 September 2020

Accepted: 14 November 2020

Published online: 4 January 2021

(C) The Author(s) 2021

\section{Solution-Processed Transparent Conducting Electrodes for Flexible Organic Solar Cells with $16.61 \%$ Efficiency}

\author{
Juanyong Wan ${ }^{1}$, Yonggao Xia ${ }^{1}$, Junfeng Fang ${ }^{2}{ }^{凶}$, Zhiguo Zhang ${ }^{3,6}{ }^{凶}$, Bingang Xu ${ }^{4}$, \\ Jinzhao Wang ${ }^{5}$, Ling $\mathrm{Ai}^{1}$, Weijie Song ${ }^{1}$, Kwun Nam Hui ${ }^{7}$, Xi Fan ${ }^{1} \bowtie$, Yongfang Li $^{3}$
}

\title{
HIGHLIGHTS
}

- The PEDOT:PSS flexible electrodes with a unique $\mathrm{CF}_{3} \mathrm{SO}_{3} \mathrm{H}$ treatment exhibited high electrical characteristics and stability.

- An energy level tuning effect was induced to create a suitable work function.

- Flexible organic solar cells yielded a record-high efficiency of $16.61 \%$, a high flexibility, and a good thermal stability.

ABSTRACT Nonfullerene organic solar cells (OSCs) have achieved breakthrough with pushing the efficiency exceeding $17 \%$. While this shed light on OSC commercialization, high-performance flexible OSCs should be pursued through solution manufacturing. Herein, we report a solution-processed flexible OSC based on a transparent conducting PEDOT:PSS anode doped with trifluoromethanesulfonic acid $\left(\mathrm{CF}_{3} \mathrm{SO}_{3} \mathrm{H}\right)$. Through a low-concentration and low-temperature $\mathrm{CF}_{3} \mathrm{SO}_{3} \mathrm{H}$ doping, the conducting polymer anodes exhibited a main sheet resistance of $35 \Omega \mathrm{sq}^{-1}$ (minimum value: $32 \Omega \mathrm{sq}^{-1}$ ), a raised work function $(\approx 5.0 \mathrm{eV})$, a superior wettability, and a high electrical stability. The high work function minimized the energy level mismatch among the anodes, hole-transporting layers and electron-donors of the active layers, thereby leading to an enhanced carrier extraction. The solution-processed flexible OSCs yielded

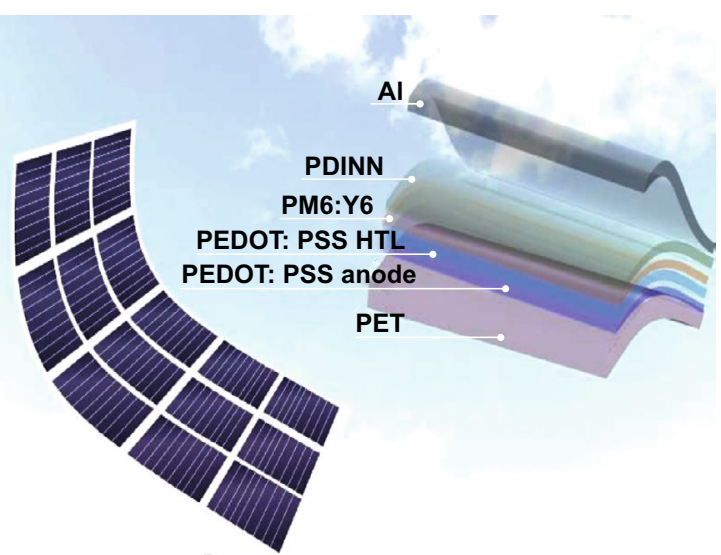
a record-high efficiency of $16.41 \%$ (maximum value: $16.61 \%$ ). Besides, the flexible OSCs afforded the 1000 cyclic bending tests at the radius of $1.5 \mathrm{~mm}$ and the long-time thermal treatments at $85^{\circ} \mathrm{C}$, demonstrating a high flexibility and a good thermal stability.

KEYWORDS Solution-processed transparent conducting electrode; Flexible organic solar cell; PEDOT:PSS; Trifluoromethanesulfonic acid doping; Solution processing

$\triangle$ Junfeng Fang, jffang@phy.ecnu.edu.cn; Zhiguo Zhang, zgzhangwhu@iccas.ac.cn; Xi Fan, fanxi@nimte.ac.cn

1 Ningbo Institute of Materials Technology and Engineering, Chinese Academy of Sciences, Ningbo 315201, People's Republic of China

2 School of Physics and Electronics Science, Engineering Research Center of Nanophotonics and Advanced Instrument, Ministry of Education, East China Normal University, Shanghai 200241, People's Republic of China

3 Beijing National Laboratory for Molecular Sciences, CAS Key Laboratory of Organic Solids, Institution of Chemistry, Chinese Academy of Sciences, Beijing 100190, People's Republic of China

4 Nanotechnology Center, Institute of Textiles and Clothing, The Hong Kong Polytechnic University, Hung Hom, Kowloon, Hong Kong 999077, People's Republic of China

5 Department of Material Science and Engineering, Hubei University, Wuhan 430062, People's Republic of China

6 State Key Laboratory of Organic/Inorganic Composites, Beijing Advanced Innovation Center for Soft Matter Science and Engineering, Beijing University of Chemical Technology, Beijing 100029, People's Republic of China

7 Joint Key Laboratory of the Ministry of Education, Institute of Applied Physics and Materials Engineering, University of Macau, Avenida da Universidade, Taipa, Macau SAR 999078, People's Republic of China 


\section{Introduction}

Flexible organic solar cells (OSCs) have become a popular research field, owing to the advantages of low cost, light weight, ease of fabrication, wearability, portability, etc. [1-16]. Transparent electrode fabrication is regarded as one of cores that determine the power conversion efficiency (PCE) and the device fabrication cost [17]. A flexible OSC requires that transparent electrodes on plastic substrates can exhibit high conductivity, high transparency, and good mechanical flexibility. However, the traditional transparent electrodes of indium tin oxide (ITO) have a low conductivity on plastic substrates and the ITO electrodes are easy to crack sharply in bending tests [18-21], making them unsuitable for application in flexible optoelectronics.

Several emerging transparent conducting materials show a promise as ITO alternatives and have the potential for large-area coverage and some degrees of mechanical flexibility. These materials include transparent conducting polymers [22-27], carbon nanotubes [28], graphene $[14,29]$, and metallic nanowires [2, 5, 6]. Among them, the solution-processed conducting polymeric films of poly(3,4-ethylenedioxythiophene):poly(4-styrenesulfonate) (PEDOT:PSS) were under intense investigation. The PEDOT:PSS films were widely used as the transparent electrode in OSCs, perovskite solar cells, light emitting diodes, etc. [17, 21]. Recent effort was devoted to the chemical doping of PEDOT:PSS films for improving the electrical characteristics. Doping strategies for the transparent PEDOT:PSS electrodes can be generally classified into a few categories: (i) metal chlorides such as $\mathrm{FeCl}_{3}$ and $\mathrm{AuCl}_{3}$ [14]; (ii) secondary polar solvents [30-32]; (iii) fluorosurfactant and Triton X-100 [33]; (iv) ionic liquids [34-36]; and (v) strong and mild acids [24-27, 37-40]. After the metal chloride and polar solvent doping, the PEDOT:PSS films exhibited a moderate electrical conductivity of $500-1000 \mathrm{~S} \mathrm{~cm}^{-1}$. Whereas, for the ionic liquid and fluorosurfactant doping, large-domain aggregates $(>0.40 \mu \mathrm{m})$ were generated in PEDOT:PSS aqueous solutions due to screening effects $[12,41]$. Although acid posttreatments avoided the generation of large-domain aggregates, both high-temperature acid treatments $\left(>140^{\circ} \mathrm{C}\right)$ and roomtemperature $98 \mathrm{wt} \% \mathrm{H}_{2} \mathrm{SO}_{4}$ treatments destroyed most of underlying plastic substrates $[15,25,37,40]$. Therefore, it is challenging to prepare a highly conductive, smooth and flexible PEDOT:PSS electrode required by flexible OSCs.
Trifluoromethanesulfonic acid $\left(\mathrm{CF}_{3} \mathrm{SO}_{3} \mathrm{H}\right)$ is a super acid with ultrahigh acidity $(p \mathrm{Ka}=-15)$ over sulfuric acid $\left(\mathrm{H}_{2} \mathrm{SO}_{4}, p \mathrm{Ka}=-3.0\right)$ and methanesulfonic acid $\left(\mathrm{CH}_{3} \mathrm{SO}_{3} \mathrm{H}\right.$, $p \mathrm{Ka}=-1.9)$; thereby it provides a strong protonation of hydrogen ions $\left(\mathrm{H}^{+}\right)$to insulating PSS for raising the film conductivity. Moreover, owing to a polarization of carbon-fluorine $(\mathrm{C}-\mathrm{F})$ polar covalent bonds of $\mathrm{CF}_{3} \mathrm{SO}_{3} \mathrm{H}$ with uncoupling charge centers, $\mathrm{CF}_{3} \mathrm{SO}_{3} \mathrm{H}$ is capable of polarizing the PEDOTs and raising the work function of the PEDOT:PSS films. It potentially minimizes the energy level mismatch among the PEDOT:PSS electrodes, PEDOT:PSS (Clevios P VP AI4083) buffer layers, and electron-donors of active blends for an effective charge transport. It should be noted that, although $98 \mathrm{wt} \%$ $\mathrm{CF}_{3} \mathrm{SO}_{3} \mathrm{H}$ treatment was mentioned before, the harsh treatment made the PEDOT:PSS films unsuitable for application into flexible optoelctronics, because underlying plastic substrates were destroyed in the requisite strong acid process (Fig. S1). Besides, a combined pre-treatment using $\mathrm{CF}_{3} \mathrm{SO}_{3} \mathrm{H}$ and ionic liquids was developed for making transistor fabrications [12]. However, acid pre-treatments caused large aggregates in PEDOT:PSS aqueous solutions, which were unfavorable for the smooth and uniform anodes required by flexible OSCs. Thus, it is necessary and urgent to develop a unique $\mathrm{CF}_{3} \mathrm{SO}_{3} \mathrm{H}$ treatment for the development of the solution-processed PEDOT:PSS electrodes for flexible OSCs.

In this work, we proposed a low-temperature and lowconcentration $\mathrm{CF}_{3} \mathrm{SO}_{3} \mathrm{H}$ post-treatment and demonstrated an efficient solution-processed flexible OSC based on the $\mathrm{CH}_{3} \mathrm{SO}_{3} \mathrm{H}$-doped PEDOT:PSS films as transparent anodes and PM6: $\mathrm{Y} 6$ as active layers. The $0.8 \mathrm{M} \mathrm{CF}_{3} \mathrm{SO}_{3} \mathrm{H}$ post-treatment at $50{ }^{\circ} \mathrm{C}$ induced a series of merits, including low sheet resistances, high work functions, superior hydrophilicities and a little acid residue, for the PEDOT:PSS anodes. The optimized flexible OSCs exhibited an efficiency of $16.41 \%$ with the maximum value of $16.61 \%$. To the best of our knowledge, $16.61 \%$ is the highest PCE for single-junction flexible OSCs reported so far. Furthermore, the solution-processed devices maintained a high flexibility and a good thermal stability. This work demonstrates the advance of the unique $\mathrm{CH}_{3} \mathrm{SO}_{3} \mathrm{H}$ post-treatment, and it provides a simple route to enable a flexible PEDOT:PSS anode with high conductivity, high work function and good stability for the realization of efficient and stable solution-processed flexible OSCs. 


\section{Experimental Section}

\subsection{Materials}

PM6 and Y6 were purchased from Solarmer Materials Inc, Beijing. PEDOT:PSS aqueous solutions (i.e., Clevios PH1000 and Clevios P VP AI4083) were purchased from Heraeus, Germany.

\subsection{Device Fabrication}

For the rigid ITO-based solar cells, glass substrates (size: $2.0 \times 2.0 \mathrm{~cm}^{2}$ ) were cleaned through using ultrasonic treatments in deionized (DI) water, acetone, and isopropyl alcohol (IPA), and then were processed in UVozone chambers for $10 \mathrm{~min}$. For the flexible solar cells, the polyethylene terephthalate (PET) plastic substrates were cleaned by IPA followed by baking at $100{ }^{\circ} \mathrm{C}$ for 10 min. Next, PEDOT:PSS aqueous solutions (PH1000) were filtered through $0.45 \mu \mathrm{m}$ syringe filter. The PH1000 solutions were spin-coated on the as-employed substrates at $3500 \mathrm{rpm}$ followed by the drying at $80{ }^{\circ} \mathrm{C}$ for $15 \mathrm{~min}$ in the air atmosphere. The spin-coating of PH1000 and the drying treatment were conducted again. Subsequently, the super acid treatment was conducted via dipping the $\mathrm{CF}_{3} \mathrm{SO}_{3} \mathrm{H}$ solutions on the PEDOT:PSS surfaces with a controlled temperature. Upon the $\mathrm{CF}_{3} \mathrm{SO}_{3} \mathrm{H}$ treatments for $5 \mathrm{~min}$, the acid residues were washed off by DI-water and IPA followed by a baking at $80{ }^{\circ} \mathrm{C}$ for $15 \mathrm{~min}$. Then, a PEDOT:PSS hole-transporting layer (Clevios P VP AI4083) was spin-coated on the PEDOT:PSS electrodes at $3000 \mathrm{rpm}$ for $30 \mathrm{~s}$, and the hole-transporting layer was dried at $100{ }^{\circ} \mathrm{C}$ for $10 \mathrm{~min}$. After that, the active layer blends of PM6:Y6 were dissolved in chloroform with 1-chloronaphthalene $(0.5 \%, \mathrm{v} / \mathrm{v})$ and were spin-coated at $3000 \mathrm{rpm}$ for $30 \mathrm{~s}$ onto the PEDOT:PSS (P VP AI4083) films. Then, perylene-diimide (PDINN) in methanol $\left(1.0 \mathrm{mg} \mathrm{mL}^{-1}\right)$ was spin-coated on the surfaces of active layers at $2000 \mathrm{rpm}$ to obtain the electron transporting layers. Finally, the Al cathodes were thermally evaporated under a pressure at $10^{-4} \mathrm{~Pa}$. The active area is $6.0 \mathrm{~mm}^{2}$. Note that metal probes were contacted with the Al top cathodes and the PEDOT:PSS bottom anodes coated with Ag pastes for the current density-voltage $(J-V)$ characteristics.

\subsection{Characterizations}

Sheet resistance was measured through using van der Pauw four-point probe method. Film thickness was conducted by a surface profile-meter (Talysurf Series II). The carrier concentration of the PEDOT:PSS electrodes was measured by the Hall measurement system (Lake Shore, 7704A) with the van der Pauw four-point probe method. UV-Vis spectra were taken on GS54T spectrophotometers (Shanghai Lengguang Technology Co., China). Film morphology was conducted through using a scanning probe microscope (SPM, VEECO Dimension 3100V) and transmission electron microscopy (TEM, TECNAI G20, FEI). The molecule structures were conducted through using Fourier transform infrared (FTIR) spectroscopy (NICOLET 6700, THermo, USA) and Raman spectroscopy (Renishaw inVia Reflex). Element compositions of the PEDOT:PSS films were conducted by X-ray photoelectron spectroscopy (XPS, XSAM800). Ultraviolet photoelectron spectra (UPS) measurements were carried out using a Kratos AXIS ULTRA DALD UPS system. $J-V$ characteristics were measured in $\mathrm{N}_{2}$-filled glove-boxes using a Keithley 2400 sourcemeter under the illumination of AM 1.5G, with a AAA solar simulator (Newport, model 94023A). The lamp was calibrated by a $2 \times 2 \mathrm{~cm}^{2}$ monocrystalline silicon reference cell (KG5 filter) provided by Newport Corporation. The light intensity was calibrated with a standard silicon detector. External quantum efficiency was conducted through the Newport quantum efficiency measurement system (ORIEL IQE 200TM) in the ambient atmosphere. The light intensity was calibrated with a standard $\mathrm{Si} / \mathrm{Ge}$ solar cell. To evaluate the device flexibility, the solar cells were bent with radii of $1.5 \mathrm{~mm}$ and underwent the 1000 cycle harsh bending. To evaluate the thermal stability, the solar cells were placed in a hot plate at $85^{\circ} \mathrm{C}$ in the glove-boxes filled with $\mathrm{N}_{2}$.

\section{Results and Discussion}

\subsection{Optical and Electrical Characteristics of PEDOT:PSS Electrodes}

Figure 1a, b plots the main sheet resistance $\left(R_{\mathrm{sh}}\right)$ and the optical transparency (T\%) at $\lambda=550 \mathrm{~nm}$ of the PEDOT:PSS electrodes with the $\mathrm{CF}_{3} \mathrm{SO}_{3} \mathrm{H}$ doping treatments. Except 
the PEDOT:PSS electrode with the $0.1 \mathrm{M} \mathrm{CF}_{3} \mathrm{SO}_{3} \mathrm{H}$ doping treatment at room temperature (RT: $\approx 20{ }^{\circ} \mathrm{C}$ ) having $R_{\mathrm{sh}}$ of $\approx 72 \Omega \mathrm{sq}^{-1}$, all the films showed a low $R_{\mathrm{sh}}$ of $35-55 \Omega \mathrm{sq}^{-1}$. We found that with the increase in the doping treatment temperatures from RT to $140{ }^{\circ} \mathrm{C}$, the $R_{\mathrm{sh}}$ of the PEDOT:PSS electrode was generally decreased. When the doping treatment temperatures were further raised from 140 to $180{ }^{\circ} \mathrm{C}$, the $R_{\mathrm{sh}}$ was slightly increased for the PEDOT:PSS electrodes with 0.3-6.0 $\mathrm{M} \mathrm{CF}_{3} \mathrm{SO}_{3} \mathrm{H}$ treatments. Through using the $0.8 \mathrm{M} \mathrm{CF}_{3} \mathrm{SO}_{3} \mathrm{H}$ treatment at $50{ }^{\circ} \mathrm{C}$, the minimum sheet resistance of the optimized PEDOT:PSS electrode reached $32 \Omega \mathrm{sq}^{-1}$, which was attributed to: (i) a strong protonation of hydrogen ions that ionized from the super acids to the insulating components of PSS, and (ii) a polarization of fluorocarbon bonds to the PEDOT molecules.
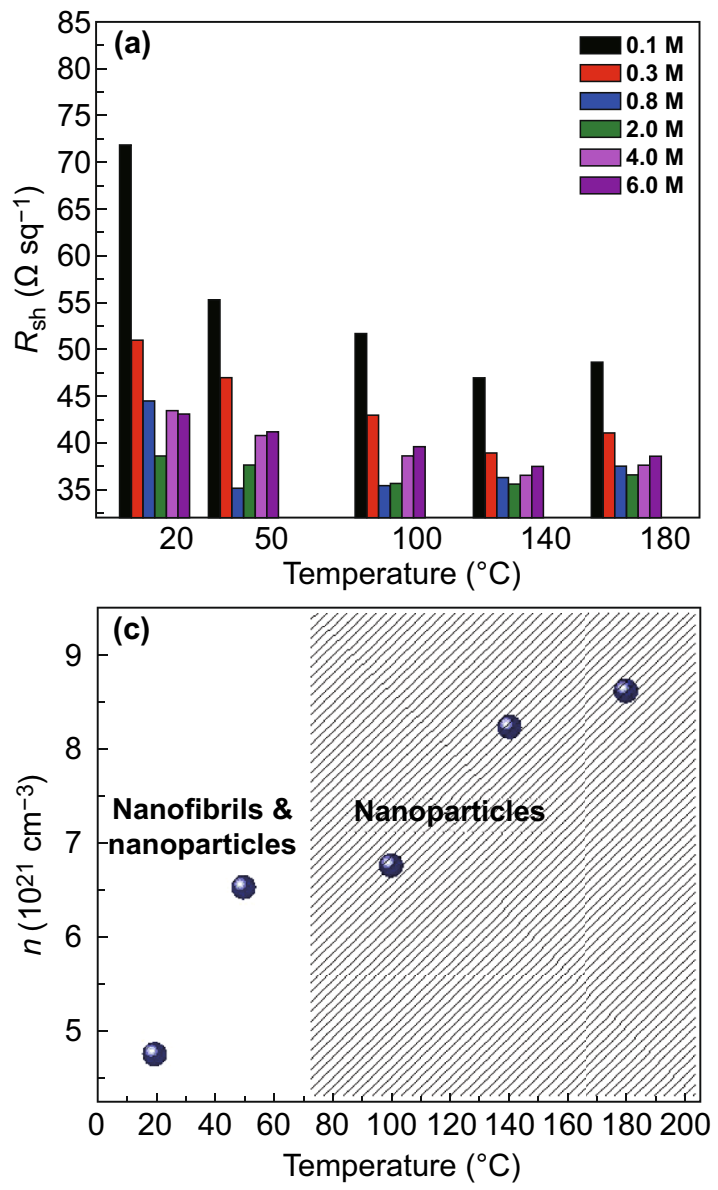

The PEDOT:PSS electrodes showed a high optical transparency that was raised with the increase in the doping treatment temperatures. For example, after the $0.8 \mathrm{M} \mathrm{CF}_{3} \mathrm{SO}_{3} \mathrm{H}$ doping treatment at $180{ }^{\circ} \mathrm{C}, \mathrm{T} \%$ was increased from 87.3 to $91.7 \%$ at $\lambda=550 \mathrm{~nm}$, which was accompanied with a morphology evolution and a reduced content of insulating PSS. With the lower concentration $(0.1-0.8 \mathrm{M}) \mathrm{CF}_{3} \mathrm{SO}_{3} \mathrm{H}$ doping treatments at no higher than $50{ }^{\circ} \mathrm{C}$, the PEDOT:PSS electrodes exhibited high optical transparencies over $87 \%$ in the visible regions of 400-550 nm (Fig. S2), which might be attributed to a large removal of hydrophilic PSS components from the PEDOT:PSS matrices as well as the formation of orderly stacked PEDOT molecules. The films with the $0.8 \mathrm{M} \mathrm{CF}_{3} \mathrm{SO}_{3} \mathrm{H}$ treatment at $50{ }^{\circ} \mathrm{C}$ having high optical and electrical characteristics should be suitable to be used as transparent electrodes for flexible OSCs.
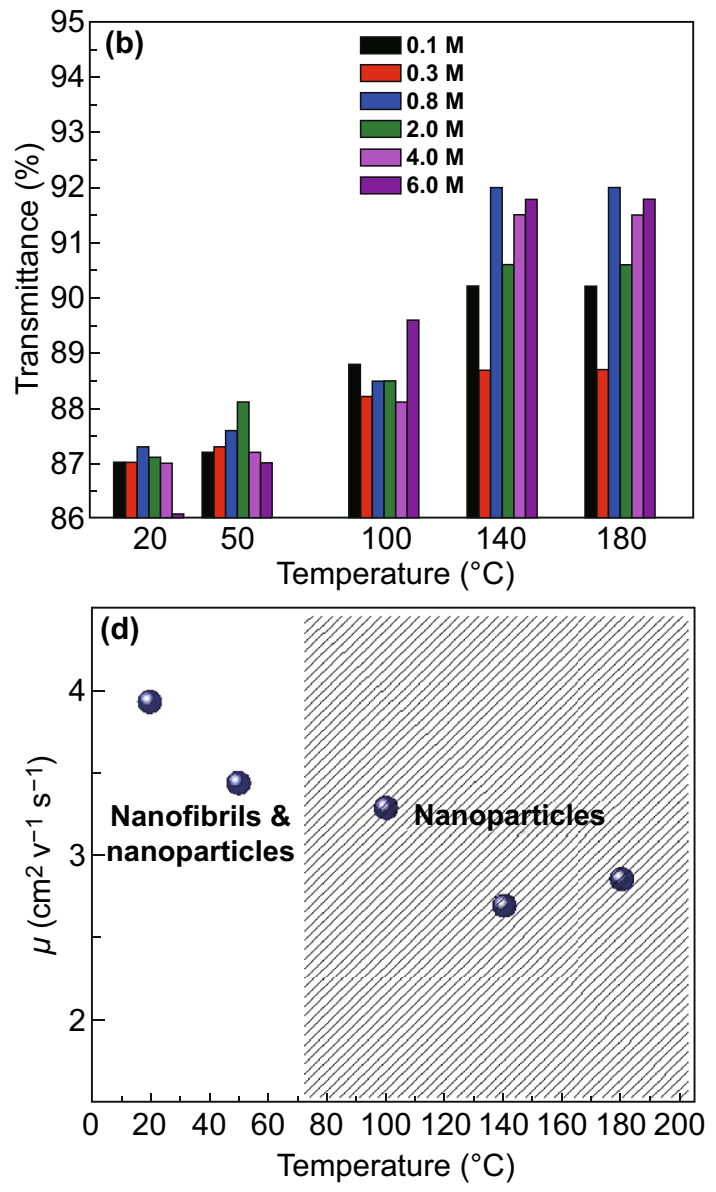

Fig. 1 Electrical and optical characteristics of PEDOT:PSS anodes. a $R_{\mathrm{sh}}$ and $\mathbf{b} T \%$ at $\lambda=550 \mathrm{~nm}$ of the PEDOT:PSS films with the different $\mathrm{CF}_{3} \mathrm{SO}_{3} \mathrm{H}$ doping treatments. $\mathbf{c} n$ and $\mathbf{d} \mu$ of the PEDOT:PSS films with the $0.8 \mathrm{M} \mathrm{CF}_{3} \mathrm{SO}_{3} \mathrm{H}$ doping treatment at a variety of processing temperatures 
We measured the carrier concentration $(n)$ of the doped PEDOT:PSS films using the Hall effect. The carrier mobility $(\mu)$ of the PEDOT:PSS films was calculated from the relationship between the electrical conductivity $(\sigma)$ and the carrier concentration: $\sigma=n e \mu$. Figure 1c, d plots the $n$ and $\mu$ of the PEDOT:PSS films doped with $0.8 \mathrm{M} \mathrm{CF}_{3} \mathrm{SO}_{3} \mathrm{H}$. With the increase in the doping treatment temperatures, $n$ was increased from 4.77 to $8.62 \mathrm{~cm}^{-3}$, mostly attributed to the high protonation of the lower concentration $\mathrm{CF}_{3} \mathrm{SO}_{3} \mathrm{H}$ to $\mathrm{PSS}\left(\mathrm{H}^{+}\right.$ionized from $\left.\mathrm{CF}_{3} \mathrm{SO}_{3} \mathrm{H}\right)$ and polarization of $\mathrm{C}-\mathrm{F}$ polar covalent bonds. A strong polarization induced weak Coulomb interactions between PEDOT and PSS, thereby leading to a favorable phase-separated morphology. The $n$ values $\left(6.52-8.62 \mathrm{~cm}^{-3}\right)$ of the PEDOT:PSS films with $0.8 \mathrm{M} \mathrm{CF}_{3} \mathrm{SO}_{3} \mathrm{H}$ treatments are comparable to the best value $\left(\approx 6.2 \mathrm{~cm}^{-3}\right)$ of the optimal PEDOT:PSS films with $98 \mathrm{wt} \%$ sulfuric acid treatments [25]. Notably, the lower concentration $\mathrm{CF}_{3} \mathrm{SO}_{3} \mathrm{H}$ treatments avoided destroying underlying plastic substrates (Fig. S1), and it would reduce substantially strong acid residues on electrode surfaces. We also found that the $\mu$ values (3.93 and $3.44 \mathrm{~cm}^{2} \mathrm{~V}^{-1} \mathrm{~s}^{-1}$ ) of the PEDOT:PSS films doped by $\mathrm{CF}_{3} \mathrm{SO}_{3} \mathrm{H}$ at low temperatures $\left(\leq 50^{\circ} \mathrm{C}\right)$ were higher than that of the PEDOT:PSS films doped by $\mathrm{CF}_{3} \mathrm{SO}_{3} \mathrm{H}$ at high temperatures ( $\geq 100^{\circ} \mathrm{C}$ ). The higher $\mu$ values were related to a morphology evolution of these doped films. The results demonstrated a high electrical characteristic achieved by the PEDOT:PSS films with the $\mathrm{CF}_{3} \mathrm{SO}_{3} \mathrm{H}$ treatments; and the low-temperature and low-concentration $\mathrm{CF}_{3} \mathrm{SO}_{3} \mathrm{H}$ treatments are compatible to thermoplastic substrates for flexible device integration.

\subsection{Morphological and Structural Characteristics of PEDOT:PSS Electrodes}

The high electrical characteristics are mostly attributed to an evolution in phase-segregated morphology and a reduced content of insulating PSS components. Figure 2 presents the morphologies of the PEDOT:PSS films (PH1000) through using SPM and TEM. As-cast films exhibited an inferior phase segregation with a low root-mean-square (RMS) roughness of $1.51 \mathrm{~nm}$ (Fig. $2 \mathrm{a}, \mathrm{g}$ ). Via the $0.8 \mathrm{M} \mathrm{CF}_{3} \mathrm{SO}_{3} \mathrm{H}$ doping at RT, the PEDOT:PSS films exhibited the physically continuous networks with a higher roughness of $2.63 \mathrm{~nm}$. The morphology differs from the cluster morphology of the conventional PEDOT:PSS films that were doped with 6 vol\% dimethylsulfoxide (DMSO) (Fig. S3). With the increase in the doping treatment temperatures to $50{ }^{\circ} \mathrm{C}$, it induced a physically continuous network that consisted of spherical/ elliptical-like nanoparticles and nanofibrils (Fig. 2c, h). The results demonstrated a favorable phase-segregated morphology, thanks to a full penetration of $\mathrm{H}+$ into the PEDOT:PSS matrix followed by the reaction $(\mathrm{H}++\mathrm{PSS}-\rightarrow \mathrm{PSSH})$. The morphology was favorable for charge-carrier transport and collection by the PEDOT:PSS anodes in solar cells. With the $\mathrm{CF}_{3} \mathrm{SO}_{3} \mathrm{H}$ treatments at the higher temperatures of 100 and $140{ }^{\circ} \mathrm{C}$, the PEDOT:PSS films showed a morphology evolution from linear/expended nanofibril-like networks to coiled small aggregated nanoparticles (Fig. 2d, e, g). The major sizes of the small nanoparticles were $20-40 \mathrm{~nm}$. By increasing the doping treatment temperatures to $180{ }^{\circ} \mathrm{C}$, the smallest nanoparticles with major sizes of 10-25 nm appeared (Fig. 2f, i), suggesting a weak Columbic attraction between the PEDOT molecules and the PSS chains. The PEDOT:PSS (PH1000) films are then characterized by the FTIR spectroscopy. As shown in Fig. S4a, the FTIR bands located between 1000 and $1100 \mathrm{~cm}^{-1}$ originate from the stretching vibrations of the PSS-H bonds [41, 42]. After the $\mathrm{CF}_{3} \mathrm{SO}_{3} \mathrm{H}$ treatments, the valleys blue-shifted and the valley's intensity became stronger, indicating the PSSH formations in the PEDOT:PSS matrices. Figure S4b shows the Raman spectra of the PEDOT:PSS (PH1000) films including the as-cast ones, and the as-doped ones with the $0.8 \mathrm{M} \mathrm{CF}_{3} \mathrm{SO}_{3} \mathrm{H}$ treatments at 50 and $140{ }^{\circ} \mathrm{C}$. The peak at $756 \mathrm{~cm}^{-1}$ corresponds to the stretching mode of $\mathrm{CF}_{3} \mathrm{SO}_{3}^{-}$[43]. The peak at $756 \mathrm{~cm}^{-1}$ wasn't observed in the films, suggesting little $\mathrm{CF}_{3} \mathrm{SO}_{3} \mathrm{H}$ residuals on the surfaces of the $\mathrm{CF}_{3} \mathrm{SO}_{3} \mathrm{H}$-doped films. The strongest band between 1400 and $1500 \mathrm{~cm}^{-1}$ originated from the $\mathrm{C}_{\alpha}=\mathrm{C}_{\beta}$ stretching vibration of the PEDOTs. The $\mathrm{C}_{\alpha}=\mathrm{C}_{\beta}$ vibration peaks in Raman spectroscopy red-shifted and were narrower in width in the as-doped PEDOT:PSS films as compared to that of the ascast films. The results indicate an evolution of the PEDOTs from benzoid structures to quinoid structures, leading to a more planar backbone. This planarity is probably attributed to more efficient charge delocalization and a higher packing order [44]. The peak at $700 \mathrm{~cm}^{-1}$ corresponds to the sym $\mathrm{C}-\mathrm{S}-\mathrm{C}$ vibrations in PEDOTs [45]. The peak had a weak intensity and became wider in width, probably attributed to the formation of the quinoid structures of the PEDOTs. 
(a)

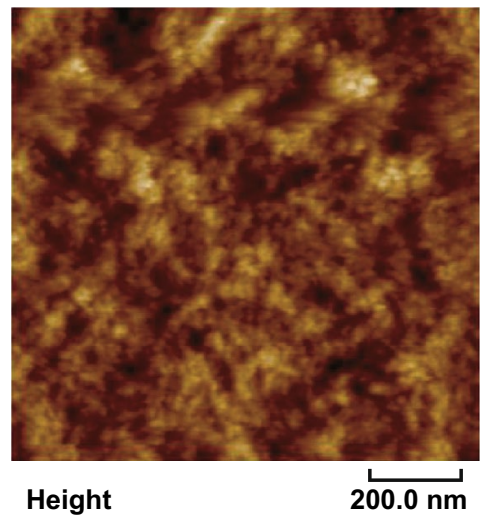

(d)

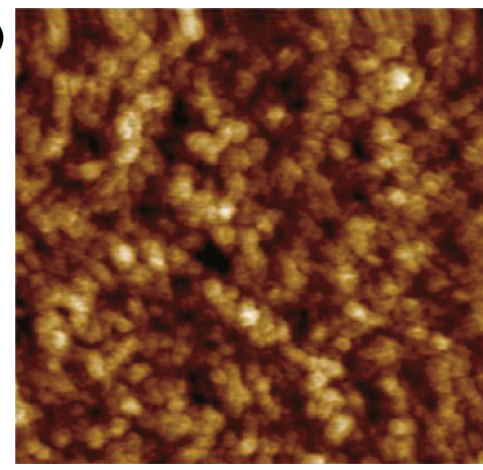

$$
\text { Height }
$$

(g)

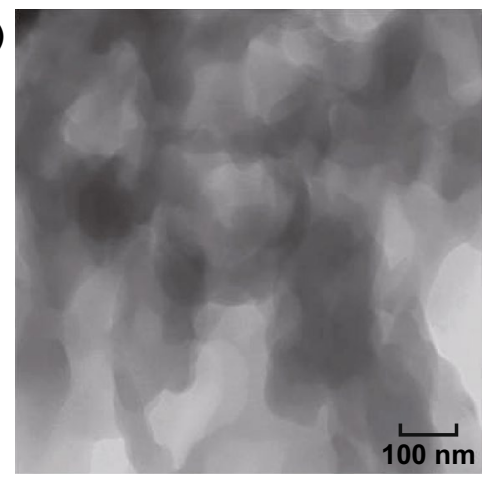

(b)

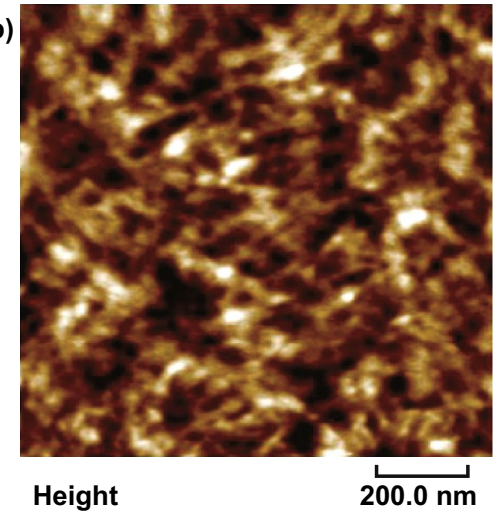

(e)

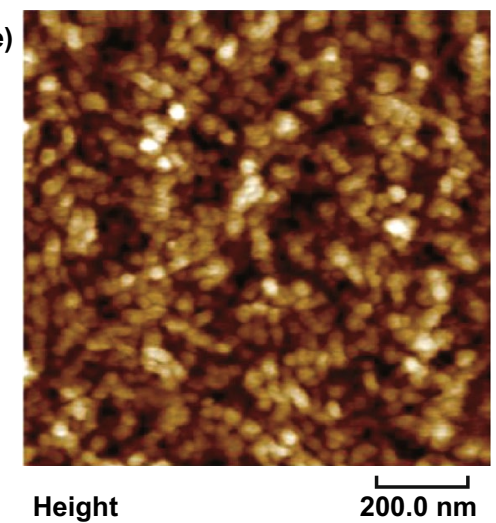

(h)

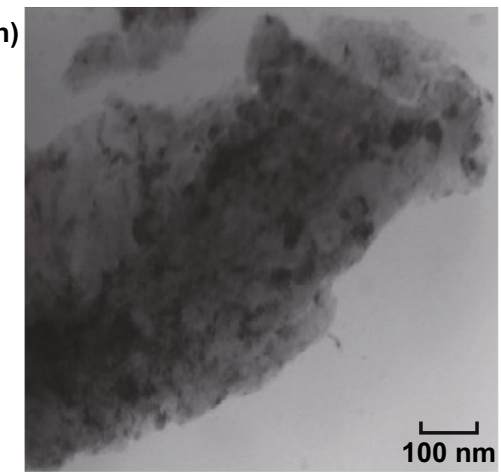

(c)

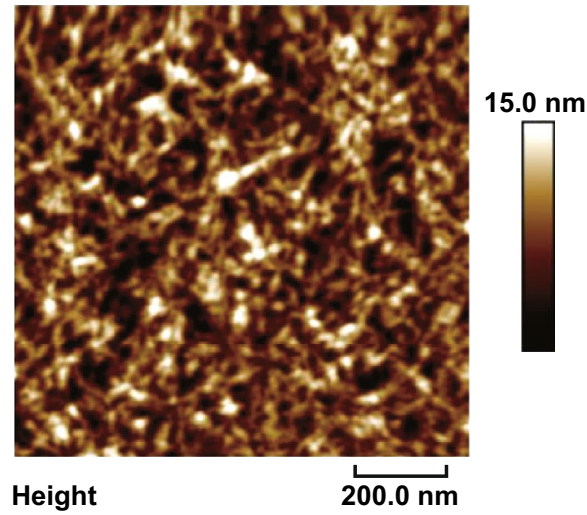

(f)
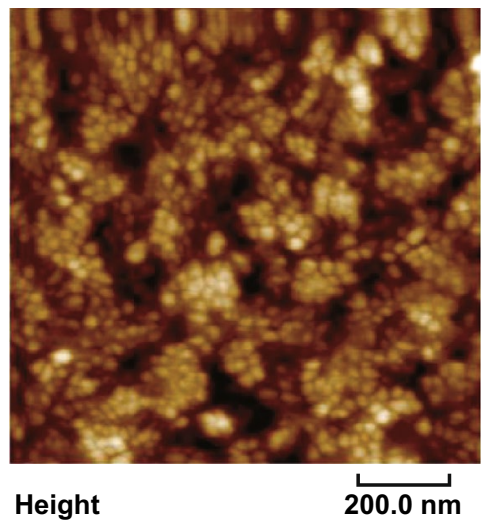

(i)

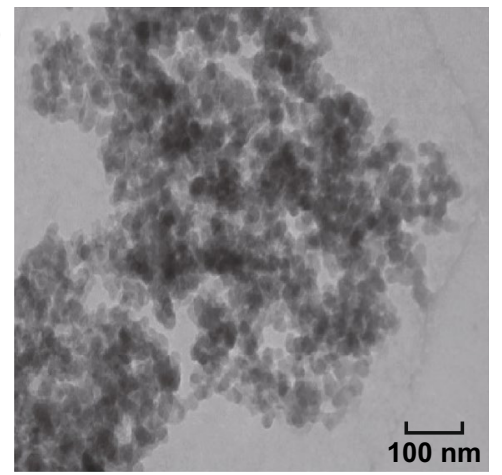

Fig. 2 Morphological characteristics of PEDOT:PSS films. a, $\mathbf{g}$ As-cast films. The films with the $0.8 \mathrm{M} \mathrm{CF}_{3} \mathrm{SO}_{3} \mathrm{H}$ treatments at the temperatures: b RT; $\mathbf{c}, \mathbf{h} 50^{\circ} \mathrm{C} ; \mathbf{d} 100{ }^{\circ} \mathrm{C} ; \mathbf{e}, \mathbf{i} 140{ }^{\circ} \mathrm{C}$; and $\mathbf{f} 180{ }^{\circ} \mathrm{C}$. Scale bar: $100 \mathrm{~nm}$ for $\mathbf{g}, \mathbf{h}$, and $\mathbf{i}$

\subsection{Components and Work Functions of PEDOT:PSS Electrodes}

To elucidate the effect of the $\mathrm{CF}_{3} \mathrm{SO}_{3} \mathrm{H}$ doping treatments on the components of the PEDOT:PSS films, we showed the XPS full spectra (Fig. S5) and the fitted curves (Fig. 3a-c). For as-cast films, the ratio of sulfur (S) atoms in sulfonate moieties of PSS to $\mathrm{S}$ atoms in thiophene rings of PEDOT (called $\mathrm{S}_{\mathrm{PSS}}: \mathrm{S}_{\mathrm{PEDOT}}$ ) is 1.26:1 (Fig. 3a), whereas for the PEDOT:PSS films with the $0.8 \mathrm{M} \mathrm{CF}_{3} \mathrm{SO}_{3} \mathrm{H}$ treatment at $50{ }^{\circ} \mathrm{C}$, the ratio is sharply decreased to $0.37: 1$ (Fig. 3b), indicating a large removal of insulating PSS from the PEDOT:PSS matrices. Note that, to accurately calculate the ratio, sulfonate moieties originated from $\mathrm{CF}_{3} \mathrm{SO}_{3} \mathrm{H}$ were considered as well. For the PEDOT:PSS films with the $0.8 \mathrm{M} \mathrm{CF}_{3} \mathrm{SO}_{3} \mathrm{H}$ treatment at $140{ }^{\circ} \mathrm{C}$, the ratio is $0.82: 1$ (Fig. 3c). The less PSS components contributed to the reduced sheet resistances. Besides, the content of the fluorine atoms is 3.75 and 7.40 atom\% for the PEDOT:PSS films doped at 50 and $140{ }^{\circ} \mathrm{C}$, respectively 

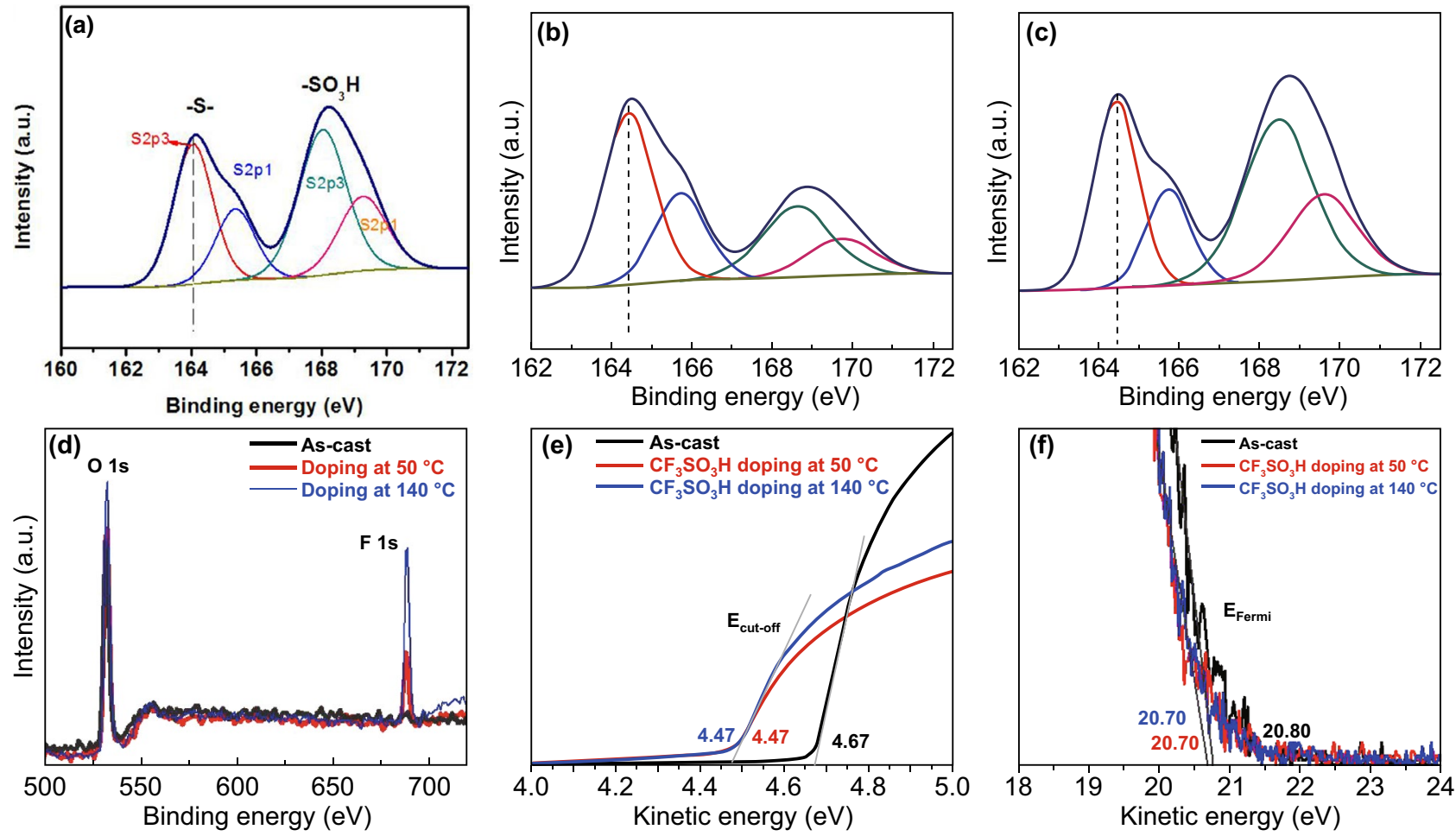

Fig. 3 Element analysis and energy levels of PEDOT:PSS films. a-c Fitted S 2p XPS of the as-cast ones for $\mathbf{a}$ and both ones doped at $50{ }^{\circ} \mathrm{C}$ for $\mathbf{b}$ and $140{ }^{\circ} \mathrm{C}$ for $\mathbf{c}$. d Fluorine contents of these films. UPS of the inelastic cutoff region for $\mathbf{e}$ and the HOMO region of the films for $\mathbf{f}$

(Fig. 3d). The electron-withdrawing fluorine groups led to the interfacial dipoles pointing toward the active layers of the OSCs. We also found that the $\mathrm{CF}_{3} \mathrm{SO}_{3} \mathrm{H}$ contents on the PEDOT:PSS film surfaces were much lower than that (14.08 atom\%) of the PEDOT:PSS films with $40 \mathrm{wt} \%$ viscous phosphoric acid treatments [15], due to the use of the lower concentration $\mathrm{CF}_{3} \mathrm{SO}_{3} \mathrm{H}$ solutions with a low viscosity. It is favored to make a smooth anode and a highquality coating of buffer layers on tops. Furthermore, we compared the binding energies of the $\mathrm{S} 2 \mathrm{p}_{3 / 2}$ emission for PEDOT to evaluate the impact of the doping treatments on the oxidation states of sulfurs of PEDOT. Binding energy of $\mathrm{S} 2 \mathrm{p}_{3 / 2}$ of PEDOT in as-cast films is $164.0 \mathrm{eV}$ [39]. Both PEDOT:PSS films doped at 50 and $140{ }^{\circ} \mathrm{C}$ showed a visible shift of $\approx 0.34 \mathrm{eV}$ toward higher binding energies of PEDOT emission, as compared to as-cast ones. The results demonstrated an evolution in the electronic environment of the sulfur atoms and a raised oxidation level of the thiophene sulfur of PEDOT molecules.

We probed the energy levels of the PEDOT:PSS films (PH1000) through UPS. Figure 3e, f shows the low kinetic energy cutoff $\left(E_{\text {cutoff }}\right)$ and the Fermi levels $\left(E_{\text {Fermi }}\right)$ of the PEDOT:PSS films including as-cast ones and $0.8 \mathrm{M}$ $\mathrm{CF}_{3} \mathrm{SO}_{3} \mathrm{H}$-doped ones. According to the relation below:

$\phi=h \nu+E_{\text {cutoff }}-E_{\text {Fermi }}$

Work function $(\Phi)$ is obtained. The $\mathrm{CF}_{3} \mathrm{SO}_{3} \mathrm{H}$-doped films exhibited a high $\Phi$ of $\approx 5.0 \mathrm{eV}(4.99 \mathrm{eV})$, which was independent of the doping treatment temperatures. It allowed a formation of Ohmic contacts, and it was favored for hole transport from active layers of OSCs to PEDOT:PSS anodes. Besides, the small offset between the $\Phi$ of PEDOT:PSS and the highest occupied molecular orbital (HOMO) of electron donors of active layers could maximize the charge extraction and minimize the recombination losses, thereby resulting in a raised built-in field for a high open-circuit voltage $\left(V_{\mathrm{OC}}\right)$ of OSCs. These results encouraged us to apply the highly conductive PEDOT:PSS anodes with a high work function into efficient solution-processed flexible OSCs.

\subsection{Device Efficiency and Flexibility}

We fabricated the ITO-free flexible OSCs based on the PEDOT:PSS anodes with the $0.8 \mathrm{M} \mathrm{CF}_{3} \mathrm{SO}_{3} \mathrm{H}$ doping treatment at the low temperature of $50{ }^{\circ} \mathrm{C}$. Notably, most of 
plastic substrates suffered from a harsh strong acid treatment at high temperatures (e.g., $>140{ }^{\circ} \mathrm{C}$ ), whereas the low-temperature and low-concentration $\mathrm{CF}_{3} \mathrm{SO}_{3} \mathrm{H}$ doping treatment avoided destroying the PET substrates, and thus it enabled the flexible PEDOT:PSS anodes. Figure 4a displays the flexible OSC structure, that is, PET $(100 \mu \mathrm{m}) / \mathrm{CF}_{3} \mathrm{SO}_{3} \mathrm{H}-$ doped PEDOT:PSS (Clevios PH1000, 75 nm)/PEDOT:PSS (Clevios P VP AI4083, 30 nm)/PM6:Y6 [46] (150 nm)/ PDINN [4] (10 nm)/Al (100 nm). The energy levels of the device components are illustrated in Fig. 4b. We also plotted the work functions of the PH1000 films including as-cast ones, the conventional ones [26, 37] soaked with $99.5 \mathrm{wt} \%$ $\mathrm{CH}_{3} \mathrm{SO}_{3} \mathrm{H}$ at RT, and $8.0 \mathrm{M} \mathrm{CH}_{3} \mathrm{SO}_{3} \mathrm{H}$ at high temperatures $\left(140{ }^{\circ} \mathrm{C}\right)$. The good matching in energy levels among the $\mathrm{CF}_{3} \mathrm{SO}_{3} \mathrm{H}$-doped PEDOT:PSS anodes, PEDOT:PSS (P VP AI4083) buffer layers and PM6 allowed an efficient hole transfer into the polymeric anodes. Figure $4 \mathrm{c}$ shows the $J-V$ curves of the flexible OSCs based on the PEDOT:PSS anodes with the $\mathrm{CF}_{3} \mathrm{SO}_{3} \mathrm{H}$ doping at 50 and $140{ }^{\circ} \mathrm{C}$, the flexible OSCs based on a commercial ITO $(\approx 180 \mathrm{~nm}) / \mathrm{PET}$ substrate, and the rigid OSCs fabricated on ITO $(\approx 110 \mathrm{~nm}) /$ glass substrates. Through using the $\mathrm{CF}_{3} \mathrm{SO}_{3} \mathrm{H}$ treatment at $50{ }^{\circ} \mathrm{C}$, the flexible devices yielded a main PCE of $16.41 \%$ with a fill factor (FF) of $74.0 \%$ and a short-circuit current density $\left(J_{\mathrm{SC}}\right)$ of $25.79 \mathrm{~mA} \mathrm{~cm}^{-2}$ under the illumination of AM $1.5 \mathrm{G}, 100 \mathrm{~mW} \mathrm{~cm}{ }^{-2}$. The PCE was higher than that (PCE:15.97\%) of flexible OSCs based on the anodes with $0.8 \mathrm{M} \mathrm{CF} 3 \mathrm{SO} 3 \mathrm{H}$ treatments at $140{ }^{\circ} \mathrm{C}$, and that (PCE: $9.69 \%$ ) of the ITO-based flexible OSCs, which was mostly attributed to the gentle $0.8 \mathrm{M} \mathrm{CF} 3 \mathrm{SO} 3 \mathrm{H}$ treatment at $50{ }^{\circ} \mathrm{C}$ that not only avoided destroying the underlying plastic substrates, but also induced the high conductivity and high work function for the PEDOT:PSS anodes. The PCE (16.41\%) was comparable to $16.96 \%$ efficiency of the control devices fabricated on ITO $(\approx 110 \mathrm{~nm}) /$ glass substrates that exhibited a FF of $76.0 \%$ and a $J_{\mathrm{SC}}$ of $25.97 \mathrm{~mA} \mathrm{~cm}^{-2}$. Figure $4 \mathrm{~d}$ shows the external quantum efficiency (EQE) of the flexible OSCs based on the PEDOT:PSS anodes with the $0.8 \mathrm{M} \mathrm{CF}_{3} \mathrm{SO}_{3} \mathrm{H}$ treatment at $50{ }^{\circ} \mathrm{C}$. The maximum EQE value reached $86.9 \%$ at $\lambda=560 \mathrm{~nm}$ and $80.8 \%$ at $\lambda=710 \mathrm{~nm}$, which demonstrated the high $J_{\mathrm{SC}}$ of $25.79 \mathrm{~mA} \mathrm{~cm}^{-2}$. Besides, the EQE spectra of the control rigid OSCs with the 110-nm-thick ITO electrodes and the flexible OSCs with the 180-nm-thick ITO electrodes are shown in Fig. S6 for reference. These results suggest that the low-temperature $\left(50^{\circ} \mathrm{C}\right)$ and low-concentration $(0.8 \mathrm{M}) \mathrm{CF}_{3} \mathrm{SO}_{3} \mathrm{H}$ treatment is suitable to prepare flexible PEDOT:PSS anodes that are promising for efficient solution-processed flexible OSCs.

To further present the advance of the $\mathrm{CF}_{3} \mathrm{SO}_{3} \mathrm{H}$-doped PEDOT:PSS anodes, we fabricated the flexible OSCs based on PEDOT:PSS anodes with $\mathrm{CH}_{3} \mathrm{SO}_{3} \mathrm{H}$ treatments. As mentioned in the literature [15, 26, 37], the PEDOT:PSS anodes were prepared via using $99.5 \mathrm{wt} \% \mathrm{CH}_{3} \mathrm{SO}_{3} \mathrm{H}$ treatments at room temperature [15, 37], and $8.0 \mathrm{M} \mathrm{CH}_{3} \mathrm{SO}_{3} \mathrm{H}$ treatments at $140{ }^{\circ} \mathrm{C}$ [26], respectively. As shown in Fig. 4e, the flexible OSCs showed an efficiency of $15.36 \%$ with a $V_{\mathrm{OC}}$ of $0.84 \mathrm{~V}$, a $J_{\mathrm{SC}}$ of $25.22 \mathrm{~mA} \mathrm{~cm}^{-2}$ and a $\mathrm{FF}$ of $72.5 \%$ for the $8.0 \mathrm{M} \mathrm{CH}_{3} \mathrm{SO}_{3} \mathrm{H}$ treatments at $140{ }^{\circ} \mathrm{C}$, and $14.79 \%$ with a $V_{\mathrm{OC}}$ of $0.84 \mathrm{~V}$, a $J_{\mathrm{SC}}$ of $24.97 \mathrm{~mA} \mathrm{~cm}^{-2}$, and a $F F$ of $70.5 \%$ for the $99.5 \mathrm{wt} \% \mathrm{CH}_{3} \mathrm{SO}_{3} \mathrm{H}$ treatments at RT. The PCE values were much lower than that (the maximum PCE: $16.61 \%$ ) of the best flexible OSCs with the PEDOT:PSS anode by the $0.8 \mathrm{M} \mathrm{CF}_{3} \mathrm{SO}_{3} \mathrm{H}$ treatment at $50{ }^{\circ} \mathrm{C}$, the $J-V$ curve of which is also shown in Fig. 4e. Table 1 summarizes the performance data of the OSC devices for reference.

The efficiency is significantly promoted through using the optimized PEDOT:PSS (PH1000) anodes that affected the hole mobility $\left(\mu_{\mathrm{h}}\right)$ of devices. The $\mu_{\mathrm{h}}$ values of three-kinds of hole-only devices with a structure of PET/PEDOT:PSS anodes/PEDOT:PSS (P VP AI4083)/PM6:Y6/Au were calculated by the space charge limited current (SCLC) model using Theott-Gurney square law [47]:

$J_{\mathrm{D}}=\frac{9}{8} \varepsilon_{0} \varepsilon_{\mathrm{r}} \mu \frac{V^{2}}{L^{3}}$

where $\varepsilon_{\mathrm{r}}$ is the dielectric constant of active layer materials, $\varepsilon_{0}$ is the permittivity of free space, $L$ is the distance between the polymeric anode and the metal cathode $(\mathrm{Au})$, which is equivalent to the thickness of active layers, and $J_{\mathrm{D}}$ is the dark current density. Figures $4 \mathrm{f}$ shows the voltage dependence of the $J_{\mathrm{D}}^{0.5}$ of the hole-only devices. The $\mu_{\mathrm{h}}$ is $1.71 \times 10^{-4}, 2.63 \times 10^{-4}$, and $3.46 \times 10^{-4} \mathrm{~cm}^{2} \mathrm{~V}^{-1} \mathrm{~s}^{-1}$ for the hole-only OSCs based on the PEDOT:PSS anodes with $8.0 \mathrm{M} \mathrm{CH}_{3} \mathrm{SO}_{3} \mathrm{H}$ treatments at $140{ }^{\circ} \mathrm{C}, 99.5 \mathrm{wt} \% \mathrm{CH}_{3} \mathrm{SO}_{3} \mathrm{H}$ treatments at RT, and $0.8 \mathrm{M} \mathrm{CF}_{3} \mathrm{SO}_{3} \mathrm{H}$ treatments at $50{ }^{\circ} \mathrm{C}$, respectively. The $\mathrm{CF}_{3} \mathrm{SO}_{3} \mathrm{H}$-doped PEDOT:PSS anode exhibited the highest hole mobility, which facilitated chargecarrier transport and collection for raising the efficiency of flexible OSCs.

The device efficiency is probably affected by the interface contacts between the PEDOT:PSS (PH1000) anodes and the PEDOT:PSS (PVP AI4083) hole-transporting layers (HTLs). In contact angle measurements, as-cast PEDOT:PSS (PH1000) films and the PEDOT:PSS anodes 

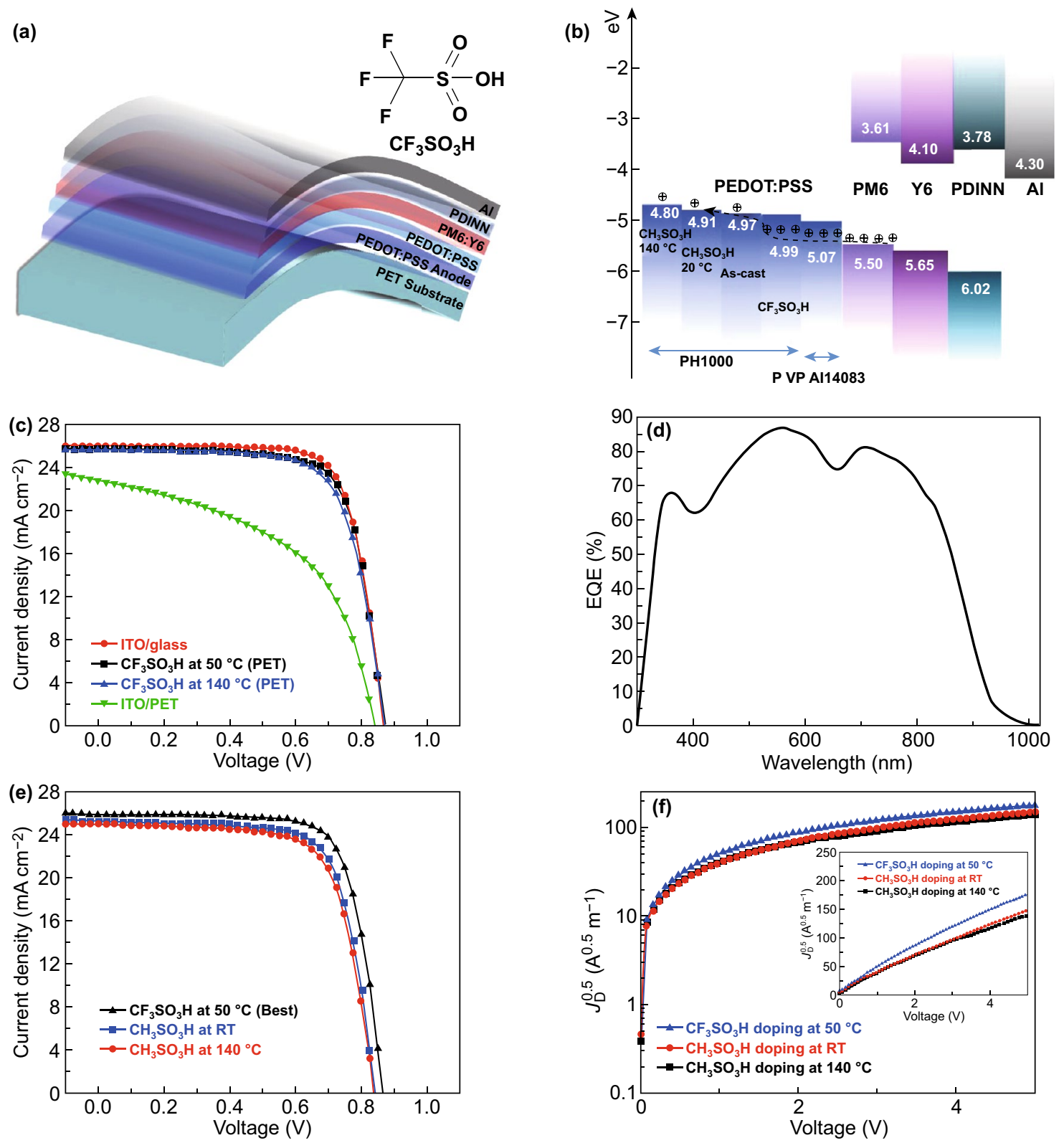

Fig. 4 Flexible OSC characteristics. a Schematic diagrams. b Energy levels. c $J-V$ characteristics of flexible OSCs with PEDOT:PSS and ITO anodes, and the OSCs fabricated on ITO/glass substrates. $\mathbf{d}$ EQE of flexible OSCs based on the PEDOT:PSS anodes with $0.8 \mathrm{M} \mathrm{CF}_{3} \mathrm{SO}_{3} \mathrm{H}$ treatments at $50{ }^{\circ} \mathrm{C}$. e $J-V$ characteristics of flexible OSCs with the $\mathrm{CH}_{3} \mathrm{SO}_{3} \mathrm{H}$-doped anodes, and the best flexible $\mathrm{OSC}$ with the $\mathrm{CF}_{3} \mathrm{SO}_{3} \mathrm{H}_{-}-\mathrm{doped}$ anodes. $f$ Electric filed dependence of $J_{\mathrm{D}}{ }^{0.5}$ of the hole-only devices based on the anodes with the $\mathrm{CF}_{3} \mathrm{SO}_{3} \mathrm{H}$ and $\mathrm{CH}_{3} \mathrm{SO}_{3} \mathrm{H}$ treatments

with $\mathrm{CH}_{3} \mathrm{SO}_{3} \mathrm{H}$ treatments at $140{ }^{\circ} \mathrm{C}$ and $\mathrm{RT}$ exhibited a mean contact angle of $38.5^{\circ}, 30.0^{\circ}$ and $23.5^{\circ}$, respectively, whereas the PEDOT:PSS anodes with $0.8 \mathrm{M} \mathrm{CF}_{3} \mathrm{SO}_{3} \mathrm{H}$ treatments at $50{ }^{\circ} \mathrm{C}$ showed the smallest contact angle of $19.0^{\circ}$ (Fig. S7). An intimate contact was formed between the PEDOT:PSS anodes with the $\mathrm{CF}_{3} \mathrm{SO}_{3} \mathrm{H}$ treatment at $50{ }^{\circ} \mathrm{C}$ and the PEDOT:PSS (PVP AI4083) HTLs, which was attributed to: (i) the intermolecular forces between rich $\mathrm{C}-\mathrm{F}$ bonds of $\mathrm{CF}_{3} \mathrm{SO}_{3} \mathrm{H}$ and sulfonate groups of PEDOT:PSS (PVP AI4083), and (ii) the hydrogen bonds between $\mathrm{CF}_{3} \mathrm{SO}_{3} \mathrm{H}$ and the sulfonate groups. The high hydrophilicity of the $\mathrm{CF}_{3} \mathrm{SO}_{3} \mathrm{H}$-doped anodes was favorable for the deposition of the PEDOT:PSS (PVP AI4083) HTLs for a high $\mu_{\mathrm{h}}$ and PCE. 
Table 1 Photovoltaic performance of the OSCs based on PEDOT:PSS and ITO electrodes

\begin{tabular}{|c|c|c|c|c|c|}
\hline Electrode & Doping and fabrication method & $V_{\mathrm{OC}}(\mathrm{V})$ & $J_{\mathrm{SC}}\left(\mathrm{mA} \mathrm{cm}^{-2}\right)$ & $\mathrm{FF}(\%)$ & $\operatorname{PCE}(\%)$ \\
\hline PEDOT:PSS/PET & $0.8 \mathrm{M} \mathrm{CF}_{3} \mathrm{SO}_{3} \mathrm{H}$ doping at $50{ }^{\circ} \mathrm{C}$ & 0.86 & 25.79 & 74.0 & $16.41( \pm 0.20)$ \\
\hline PEDOT:PSS/PET & $0.8 \mathrm{M} \mathrm{CF}_{3} \mathrm{SO}_{3} \mathrm{H}$ doping at $50{ }^{\circ} \mathrm{C}$ & 0.86 & 25.85 & 74.8 & 16.61 (Best) \\
\hline PEDOT:PSS/PET & $0.8 \mathrm{M} \mathrm{CF}_{3} \mathrm{SO}_{3} \mathrm{H}$ doping at $140{ }^{\circ} \mathrm{C}$ & 0.86 & 25.68 & 72.3 & $15.97( \pm 0.26)$ \\
\hline ITO $(180 \mathrm{~nm}) / \mathrm{PET}$ & Magnetron sputtering & 0.84 & 22.74 & 50.7 & $9.69( \pm 0.41)$ \\
\hline ITO $(110 \mathrm{~nm}) /$ glass & Magnetron sputtering & 0.84 & 25.97 & 76.0 & $16.96( \pm 0.13)$ \\
\hline PEDOT:PSS/PET & $8.0 \mathrm{M} \mathrm{CH}_{3} \mathrm{SO}_{3} \mathrm{H}$ doping at $140^{\circ} \mathrm{C}$ & 0.84 & 25.22 & 72.5 & $15.36( \pm 0.31)$ \\
\hline PEDOT:PSS /PET & $99.5 \mathrm{wt} \% \mathrm{CH}_{3} \mathrm{SO}_{3} \mathrm{H}$ doping at $\mathrm{RT}$ & 0.84 & 24.97 & 70.5 & $14.79( \pm 0.26)$ \\
\hline
\end{tabular}

Over ten devices were reproduced to confirm the mean PCE

We also observed that the $0.8 \mathrm{M} \mathrm{CF}_{3} \mathrm{SO}_{3} \mathrm{H}$ treatment at $50{ }^{\circ} \mathrm{C}$ induced the higher $\Phi$ of the anodes and the PEDOT:PSS (PVP AI4083)-coated anodes. As calculated from Fig. 5a, the $\Phi$ of the $\mathrm{CH}_{3} \mathrm{SO}_{3} \mathrm{H}$-doped control anodes and the control anodes coated with PEDOT:PSS (PVP AI4083) is 4.54 and $4.89 \mathrm{eV}$, respectively. The difference (4.54 vs $4.99 \mathrm{eV}$ ) in $\Phi$ of both $\mathrm{CH}_{3} \mathrm{SO}_{3} \mathrm{H}$ - and $\mathrm{CF}_{3} \mathrm{SO}_{3} \mathrm{H}$-doped PEDOT:PSS anodes is related to the polar natures of the acids employed. It suggests that fluorocarbon bonds of $\mathrm{CF}_{3} \mathrm{SO}_{3} \mathrm{H}$ provide a large dipole moment. When PEDOT:PSS (PVP AI4083) was coated on the optimized PEDOT:PSS anodes with the $0.8 \mathrm{M} \mathrm{CF}_{3} \mathrm{SO}_{3} \mathrm{H}$ treatment at $50{ }^{\circ} \mathrm{C}$, the $\Phi$ was improved to be $5.07 \mathrm{eV}$ (Fig. 5b). The match $(4.99,5.07$ and $5.50 \mathrm{eV})$ in the energy levels of the $\mathrm{CF}_{3} \mathrm{SO}_{3} \mathrm{H}$-doped PEDOT:PSS anode, HTL and PM6 allowed efficient hole transfer into the polymeric anodes. As a result, the efficiency of the solution-processed flexible OSCs was maximized.

The flexible OSCs have the advantage of high mechanical flexibility over the devices fabricated on ITO $(180 \mathrm{~nm}) /$ PET substrates, as shown in Fig. 6a. With 1,000 cyclic bending at $r$ of $1.5 \mathrm{~mm}$, the flexible devices based on the $\mathrm{CF}_{3} \mathrm{SO}_{3} \mathrm{H}$-doped PEDOT:PSS anodes maintained 94.4\% of the initial efficiency, whereas the devices with the ITO $(\approx 180 \mathrm{~nm}) /$ PET substrates showed a large drop in PCE down to $11.0 \%$ of the initial value at $r$ of $1.5 \mathrm{~mm}$, that meant, active regions of the ITO electrodes had been scrapped to restrain charge-carrier collections. We found that, for the small bending at the radius of $1.5 \mathrm{~mm}$, the PEDOT:PSS anodes coated on the PET substrates $\left(2 \times 2 \mathrm{~cm}^{2}\right.$; two edges were coated with Ag pastes) had no visible increase in resistance, while the resistance of the ITO/PET was increased to 3 orders of magnitude (from 1 to over 2,800), as shown in Fig. S8; this implies a structure damage of the ITO films with crack generations.

\subsection{Device Stability}

Furthermore, we investigated the thermal stability of the PEDOT:PSS anodes and the as-integrated flexible OSCs. The PEDOT:PSS anodes were thermal annealed at $85^{\circ} \mathrm{C}$ in the air atmosphere (relative humidity: 85\%). As shown in Fig. 6b, the sheet resistance of the PEDOT:PSS anodes was increased by $\approx 3.6 \%$ for the $168 \mathrm{~h}$ testing and by $\approx 6.9 \%$ for $500 \mathrm{~h}$ testing. The PEDOT:PSS anodes had a slight increase in $R_{\mathrm{sh}}$ from 35.0 to $37.4 \Omega \mathrm{sq}^{-1}$ in the long-time thermal process for $500 \mathrm{~h}$. A high thermal stability of the PEDOT:PSS anodes is energetically favored to raise the performance stability of the flexible OSCs. Figure $6 \mathrm{c}-\mathrm{f}$ shows the photovoltaic parameters $\left(V_{\mathrm{OC}}\right.$, FF, $J_{\mathrm{SC}}$, and PCE) of the flexible OSCs based on the optimized PEDOT:PSS anodes as a function of thermal processing time, respectively. Notably, the flexible OSCs were thermally processed at $85{ }^{\circ} \mathrm{C}$ for $200 \mathrm{~h}$ in an inert glove-box filled with nitrogen $\left(\mathrm{N}_{2}\right)$. Obviously, $V_{\mathrm{OC}}$ is almost independent of the thermal processing times. The FF of the flexible devices changed a little, and it was of a high value (higher than 73.0\%) for the flexible OSCs with the thermal treatment for $25 \mathrm{~h}$. The FF of the flexible OSCs with the thermal treatment for $200 \mathrm{~h}$ is $71.6 \%$, which was a little lower than that of the flexible OSCs in a shorter thermal process. However, the $J_{\mathrm{SC}}$ of the flexible OSCs changed significantly in the thermal process. As mentioned above, the flexible OSCs with the optimized PEDOT:PSS anodes showed the initial $J_{\mathrm{SC}}$ of $25.78 \mathrm{~mA} \mathrm{~cm}^{-2}$. Increasing the processing time to 150 and $200 \mathrm{~h}$ led to a lower $J_{\mathrm{SC}}$ of 24.51 and $24.23 \mathrm{~mA} \mathrm{~cm}^{-1}$, respectively. Thus, the PCE was decreased from the initial value of $16.41 \%$ to $14.92 \%$ in the thermal stability test. The decrease in PCE might be attributed to the insulating PSS components of the PEDOT:PSS anodes and P VPAI 4083 buffer layers that absorbed moisture (e.g., alcohols, $\mathrm{H}_{2} \mathrm{O}$ ), leading to a volume expansion. Besides, 

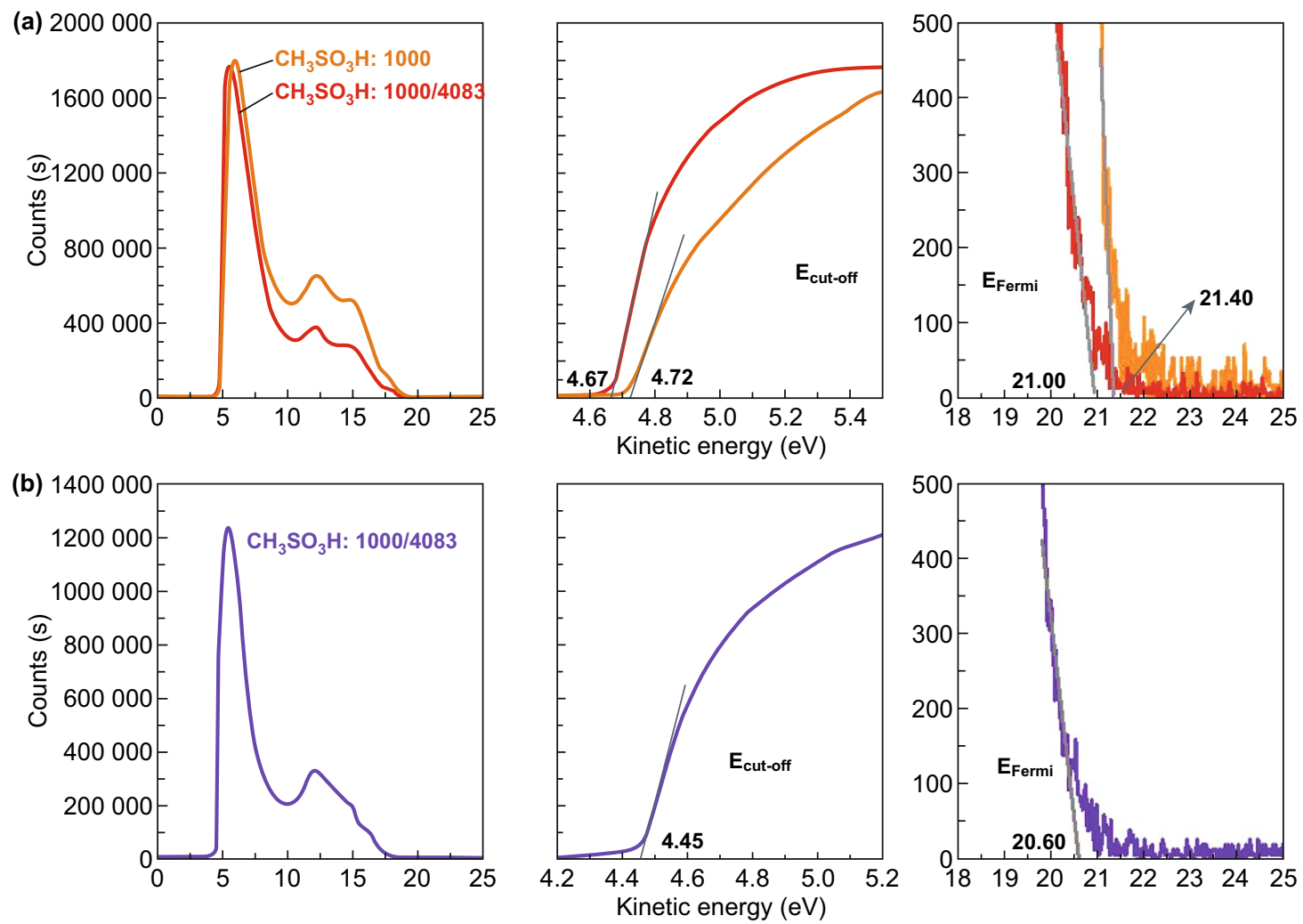

Fig. 5 Work functions of the films. a UPS of the polymeric anodes with $\mathrm{CH}_{3} \mathrm{SO}_{3} \mathrm{H}$ treatments and the PEDOT:PSS (P VP AI4083)-coated anodes. b UPS of the $\mathrm{CF}_{3} \mathrm{SO}_{3} \mathrm{H}$-doped anodes coated with PEDOT:PSS (P VP AI4083) buffer layers

the rigid main-chain structures and irregular arrangement of PDINN molecules potentially caused a contact issue at interfaces and an electrical stability concern in the thermal process. The performance stability of solution-processed flexible devices would be promoted through removing PSS components from the PEDOT:PSS matrices, and employing stable buffer layers for an interface shield in the future.

\section{Conclusions}

We demonstrated the flexible OSCs based on the $0.8 \mathrm{M}$ $\mathrm{CF}_{3} \mathrm{SO}_{3} \mathrm{H}$-doped PEDOT:PSS anodes and PM6:Y6 active layers. The flexible devices yielded the power conversion efficiency of $16.41 \%$ with the maximum value of $16.61 \%$. It was mostly attributed to the low-temperature doping treatment using lower concentration $\mathrm{CF}_{3} \mathrm{SO}_{3} \mathrm{H}$ containing fluorine groups that endowed the PEDOT:PSS anodes with high optical and electrical characteristics and a higher work function $(\approx 5.0 \mathrm{eV})$. The $\mathrm{CF}_{3} \mathrm{SO}_{3} \mathrm{H}$-doped PEDOT:PSS anodes showed a favorable phase-separated morphology with physically continuous networks; and the films had a high charge concentration $\left(6.54 \times 10^{21} \mathrm{~cm}^{-3}\right)$ and mobility $\left(3.44 \mathrm{~cm}^{2} \mathrm{~V}^{-1} \mathrm{~s}^{-1}\right)$, accounting for a low sheet resistance. The work function was raised by the electron-withdrawing fluorine groups of $\mathrm{CF}_{3} \mathrm{SO}_{3} \mathrm{H}$ that reduced the charge recombination loss at interfaces, substantially accounting for the improvement in $V_{\mathrm{OC}}$. Besides, the $\mathrm{CF}_{3} \mathrm{SO}_{3} \mathrm{H}$-doped PEDOT:PSS anodes exhibited a better wettability, resulting in an intimate contact with the hole-transporting layers (P VP AI4083). The PCE of the solution-processed flexible OSCs was maintained well in the bending tests, in which $94.4 \%$ of the initial value was retained after 1000 cyclic bending at $r$ of $1.5 \mathrm{~mm}$. The solution-processed flexible OSCs also exhibited a good thermal stability in the $200 \mathrm{~h}$ thermal process at $85^{\circ} \mathrm{C}$, i.e., a decrease by $9.1 \%$ in PCE in the stability test. This work demonstrates a solution-processed flexible OSC with a high efficiency, a high flexibility and a good thermal stability. It widens the adaptation of the flexible PEDOT:PSS anodes into high-performance flexible optoelectronics. 

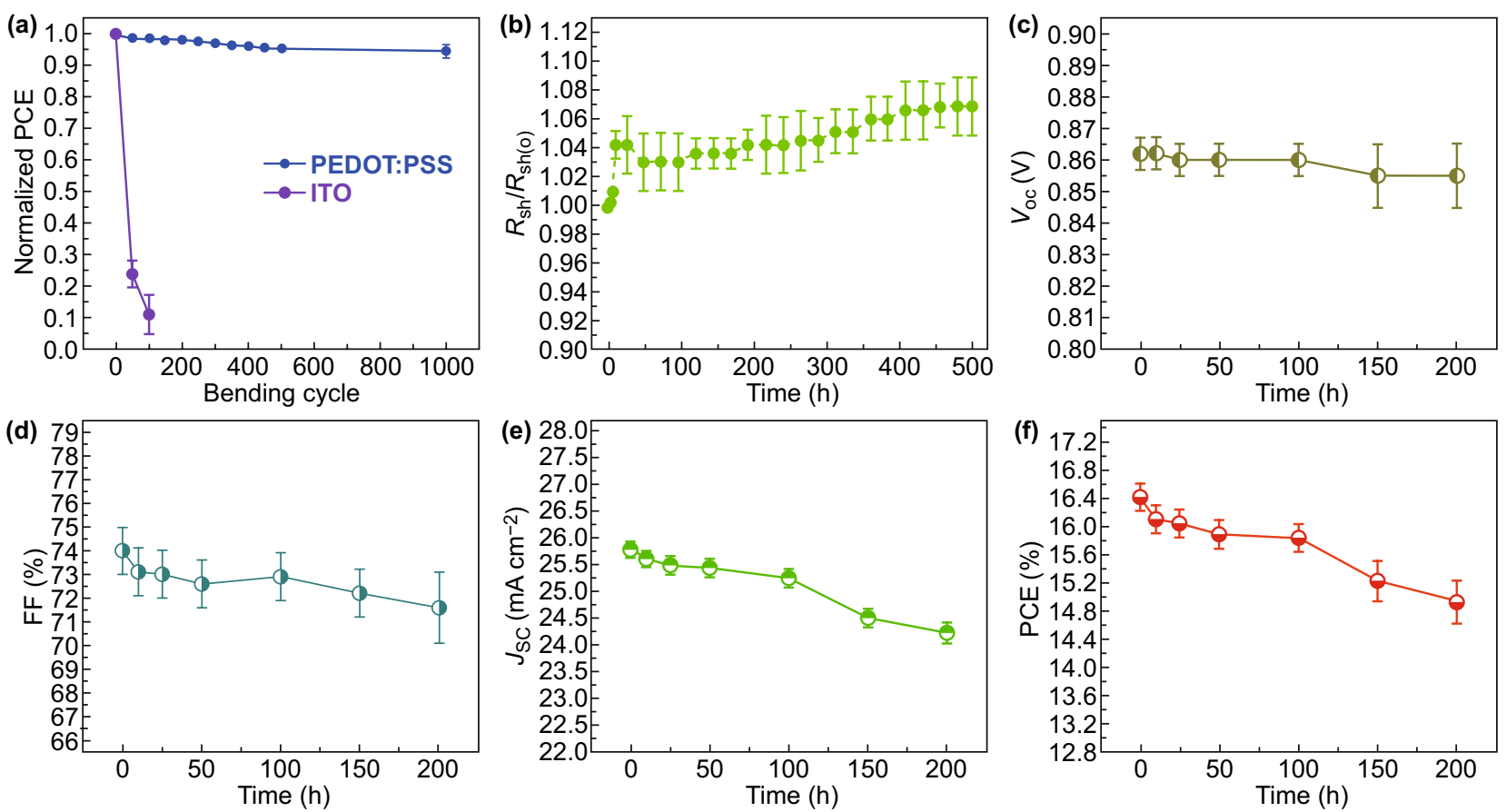

Fig. 6 Mechanical property and thermal stability of the flexible OSCs. a Profiles of normalized PCE of flexible OSCs based on the $\mathrm{CF}_{3} \mathrm{SO}_{3} \mathrm{H}$-doped anodes and ITO in harsh flexing tests at $r$ of $1.50 \mathrm{~mm}$. b $R_{\text {sh }}$ versus the thermal processing time for the $\mathrm{CF}_{3} \mathrm{SO}_{3} \mathrm{H}_{-}-\mathrm{doped}$ PEDOT:PSS anodes under $85{ }^{\circ} \mathrm{C} / 85 \%$ relative humidity conditions. Profiles of photovoltaic parameters of the flexible OSCs based on the $0.8 \mathrm{M}$ $\mathrm{CF}_{3} \mathrm{SO}_{3} \mathrm{H}$-doped anodes as a function of the thermal processing time: $\mathbf{c} V_{\mathrm{OC}}, \mathbf{d ~ F F}, \mathbf{e} J_{\mathrm{SC}}$, and $\mathbf{f} \mathrm{PCE}$

Acknowledgements The authors acknowledge funding from the National Natural Science Foundation of China (61974150 and 51773213), Key Research Program of Frontier Sciences, CAS (QYZDB-SSW-JSC047), the Fundamental Research Funds for the Central Universities, the CAS-EU S\&T cooperation partner program (174433KYSB20150013), and the Natural Science Foundation of Ningbo (2018A610135).

Open Access This article is licensed under a Creative Commons Attribution 4.0 International License, which permits use, sharing, adaptation, distribution and reproduction in any medium or format, as long as you give appropriate credit to the original author(s) and the source, provide a link to the Creative Commons licence, and indicate if changes were made. The images or other third party material in this article are included in the article's Creative Commons licence, unless indicated otherwise in a credit line to the material. If material is not included in the article's Creative Commons licence and your intended use is not permitted by statutory regulation or exceeds the permitted use, you will need to obtain permission directly from the copyright holder. To view a copy of this licence, visit http://creativecommons.org/licenses/by/4.0/.

Electronic supplementary material The online version of this article (https://doi.org/10.1007/s40820-020-00566-3) contains supplementary material, which is available to authorized users.

\section{References}

1. C.W. Tang, Two-layer organic photovoltaic cell. Appl. Phys. Lett. 48, 183-185 (1986). https://doi.org/10.1063/1.96937

2. T.Y. Qu, L.J. Zuo, J.D. Chen, X.L. Shi, T. Zhang et al., Biomimetic electrodes for flexible organic solar cells with efficiencies over 16\%. Adv. Opt. Mater. 8, 2000669 (2020). https:// doi.org/10.1002/adom.202000669

3. G. Yu, J. Gao, J.C. Hummelen, F. Wudl, A.J. Heeger, Polymer photovoltaic cells: enhanced efficiencies via a network of internal donor-acceptor heterojunctions. Science 270, 1789 (1995). https://doi.org/10.1126/science.270.5243.1789

4. J. Yao, B. Qiu, Z.G. Zhang, L. Xue, R. Wang et al., Cathode engineering with perylene-diimide interlayer enabling over $17 \%$ efficiency single-junction organic solar cells. Nat. Commun. 11, 2726 (2020). https://doi.org/10.1038/s4146 7-020-16509-w

5. X.B. Chen, G.Y. Xu, G. Zeng, H.W. Gu, H.Y. Chen et al., Realizing ultrahigh mechanical flexibility and $>15 \%$ efficiency of flexible organic solar cells via a "welding" flexible transparent electrode. Adv. Mater. 32, 1908478 (2020). https ://doi.org/10.1002/adma.201908478

6. Y.N. Sun, M.J. Chang, L.X. Meng, X.J. Wan, H.H. Gao et al., Flexible organic photovoltaics based on water-processed 
silver nanowire electrodes. Nat. Electron. 2, 513-520 (2019). https://doi.org/10.1038/s41928-019-0315-1

7. M. Kaltenbrunner, G. Adam, E.D. Głowacki, M. Drack, R. Schwödiauer et al., Flexible high power-per-weight perovskite solar cells with chromium oxide-metal contacts for improved stability in air. Nat. Mater. 14, 1032-1039 (2015). https://doi.org/10.1038/NMAT4388

8. S.M. Zhang, F. Cicoira, Flexible self-powered biosensors. Nature 561, 466-467 (2018). https://doi.org/10.1038/d4158 6-018-06788-1

9. G. Zhao, W. Wang, T. Bae, S. Lee, C. Mun et al., Stable ultrathin partially oxidized copper film electrode for highly efficient flexible solar cells. Nat. Commun. 6, 8830 (2015). https://doi.org/10.1038/ncomms9830

10. Y.B. Cheng, A. Pascoe, F. Huang, Y. Peng, Print flexible solar cells. Nature 539, 488 (2016). https://doi. org/10.1038/539488a

11. Y.W. Li, L. Meng, Y.M. Yang, G. Xu, Z. Hong et al., Highefficiency robust perovskite solar cells on ultrathin flexible substrates. Nat. Commun. 7, 75-81 (2016). https://doi. org/10.1038/ncomms 10214

12. Y. Wang, C.X. Zhu, R. Pfattner, H.P. Yan, L.H. Jin et al., A highly stretchable, transparent, and conductive polymer. Sci. Adv. 3, e1602076 (2017). https://doi.org/10.1126/sciad v. 1602076

13. Y.K. Zhang, Z. Wu, P. Li, L.K. Ono, Y. Qi et al., Fully solution-processed TCO-free semitransparent perovskite solar cells for tandem and flexible applications. Adv. Energy Mater. 8, 1701569 (2018). https://doi.org/10.1002/ aenm.201701569

14. Z.K. Liu, J.H. Li, F. Yan, Package-free flexible organic solar cells with graphene top electrodes. Adv. Mater. 25, 42964301 (2013). https://doi.org/10.1002/adma.201205337

15. X. Fan, B. Xu, S. Liu, C. Cui, J. Wang et al., Transferprinted PEDOT:PSS electrodes using mild acids for high conductivity and improved stability with application to flexible organic solar cells. ACS Appl. Mater. Interfaces 8, 14029-14036 (2016). https://doi.org/10.1021/acsami.6b013 89

16. H. Kang, S. Jung, S. Jeong, G. Kim, K. Lee, Polymer-metal hybrid transparent electrodes for flexible electronics. Nat. Commun. 6, 6503 (2015). https://doi.org/10.1038/ncomm s7503

17. H. Kang, G. Kim, J. Kim, S. Kwon, H. Kim et al., Bulk-heterojunction organic solar cells: five core technologies for their commercialization. Adv. Mater. 28, 7821-7861 (2016). https ://doi.org/10.1002/adma.201601197

18. R. Søndergaard, M. Hösel, D. Angmo, T.T. Larsen-Olsen, F.C. Krebs, Roll-to-roll fabrication of polymer solar cells. Mater. Today 15, 36-49 (2012). https://doi.org/10.1016/S1369 -7021(12)70019-6

19. C.G. Granqvist, Transparent conductors as solar energy materials: a panoramic review. Sol. Energy Mater. Sol. Cells 91, 1529-1598 (2007). https://doi.org/10.1016/j.solma t.2007.04.031
20. S.I. Na, S.S. Kim, J. Jo, D.Y. Kim, Efficient and flexible ITO-free organic solar cells using highly conductive polymer anodes. Adv. Mater. 20, 4061-4067 (2008). https://doi. org/10.1002/adma.200800338

21. X. Fan, W.Y. Nie, H. Tsai, N.X. Wang, H.H. Huang et al., PEDOT:PSS for flexible and stretchable electronics: modifications, strategies and applications. Adv. Sci. 6, 1900813 (2019). https://doi.org/10.1002/advs.201900813

22. X.T. Hu, X.C. Meng, L. Zhang, Y.Y. Zhang, Z.R. Cai et al., A mechanically robust conducting polymer network electrode for efficient flexible perovskite solar cells. Joule 3, 2205 (2019). https://doi.org/10.1016/j.joule.2019.06.011

23. Y.H. Kim, C. Sachse, M.L. Machala, C. May, L. MüllerMeskamp et al., Highly conductive PEDOT:PSS electrode with optimized solvent and thermal post-treatment for ITOfree organic solar cells. Adv. Funct. Mater. 21, 1076-1081 (2011). https://doi.org/10.1002/adfm.201002290

24. Y.J. Xia, K. Sun, J.Y. Ouyang, Solution-processed metallic conducting polymer films as transparent electrode of optoelectronic devices. Adv. Mater. 24, 2436-2440 (2012). https://doi. org/10.1002/adma.201104795

25. N. Kim, S. Kee, S.H. Lee, B.H. Lee, Y.H. Kahng et al., Highly conductive PEDOT:PSS nanofibrils induced by solution-processed crystallization. Adv. Mater. 26, 2268-2272 (2014). https://doi.org/10.1002/adma.201304611

26. K. Sun, P.C. Li, Y.J. Xia, J.L. Chang, J.Y. Ouyang, Transparent conductive oxide-free perovskite solar cells with PEDOT:PSS as transparent electrode. ACS Appl. Mater. Interfaces 7, 15314-15320 (2015). https://doi.org/10.1021/acsami.5b03171

27. X. Fan, J.Z. Wang, H.B. Wang, X. Liu, H. Wang, Bendable ITO-free organic solar cells with highly conductive and flexible PEDOT:PSS electrodes on plastic substrates. ACS Appl. Mater. Interfaces 7, 16287-16295 (2015). https://doi. org/10.1021/acsami.5b02830

28. I. Jeon, T. Chiba, C. Delacou, Y. Guo, A. Kaskela et al., Single-walled carbon nanotube film as electrode in indium-free planar heterojunction perovskite solar cells: investigation of electron-blocking layers and dopants. Nano Lett. 15, 66656671 (2015). https://doi.org/10.1021/acs.nanolett.5b02490

29. Z.K. Liu, P. You, C. Xie, G.Q. Tang, F. Yan, Ultrathin and flexible perovskite solar cells with graphene transparent electrodes. Nano Energy 28, 151-157 (2016). https://doi. org/10.1016/j.nanoen.2016.08.038

30. J.Y. Oh, S. Kim, H.-K. Baik, U. Jeong, Conducting polymer dough for deformable electronics. Adv. Mater. 28, 4455 (2016). https://doi.org/10.1002/adma.201502947

31. J.Y. Ouyang, "Secondary doping" methods to significantly enhance the conductivity of PEDOT:PSS for its application as transparent electrode of optoelectronic devices. Displays 34, 423-436 (2013). https://doi.org/10.1016/j.displa.2013.08.007

32. B.J. Worfolk, S.C. Andrews, S. Park, J. Reinspach, N. Liu et al., Ultrahigh electrical conductivity in solution-sheared polymeric transparent films. Proc. Natl. Acad. Sci. USA 112, 14138-14143 (2015). https://doi.org/10.1073/pnas.15099 58112 
33. D.J. Lipomi, J.A. Lee, M. Vosgueritchian, B.C.-K. Tee, J.A. Bolander et al., Electronic properties of transparent conductive films of PEDOT:PSS on stretchable substrates. Chem. Mater. 24, 373-382 (2012). https://doi.org/10.1021/cm203216m

34. S. Kee, N. Kim, B.S. Kim, S. Park, Y.H. Jang et al., Controlling molecular ordering in aqueous conducting polymers using ionic liquids. Adv. Mater. 28, 8625-8631 (2016). https://doi. org/10.1002/adma.201505473

35. M. Döbbelin, R. Marcilla, M. Salsamendi, C. Pozo-Gonzalo, P.M. Carrasco et al., Influence of ionic liquids on the electrical conductivity and morphology of PEDOT:PSS films. Chem. Mater. 19, 2147-2149 (2007). https://doi.org/10.1021/cm070 $398 \mathrm{z}$

36. C. Badre, L. Marquant, A.M. Alsayed, L.A. Hough, Highly conductive poly(3,4-ethylenedioxythiophene):poly (styrenesulfonate) films using 1-ethyl-3-methylimidazolium tetracyanoborate ionic liquid. Adv. Funct. Mater. 22, 2723-2727 (2012). https://doi.org/10.1002/adfm.201200225

37. W. Song, X. Fan, B. Xu, F. Yan, H. Cui et al., All solutionprocessed metal oxide-free flexible organic solar cells with over 10\% efficiency. Adv. Mater. 30, 1800075 (2018). https:// doi.org/10.1002/adma.201800075

38. C. Yeon, S.J. Yun, J. Kim, J.W. Lim, PEDOT:PSS films with greatly enhanced conductivity via nitric acid treatment at room temperature and their application as Pt/TCO-free counter electrodes in dye-sensitized solar cells. Adv. Electron. Mater. 1, 1500121 (2015). https://doi.org/10.1002/aelm.201500121

39. L. Bießmann, N. Saxena, N. Hohn, M.A. Hossain, J.G.C. Veinot et al., Highly conducting, transparent PEDOT:PSS polymer electrodes from post-treatment with weak and strong acids. Adv. Electron. Mater. 5, 1800654 (2019). https://doi. org/10.1002/aelm.201800654

40. W. Meng, R. Ge, Z.F. Li, J.H. Tong, T.F. Liu et al., Conductivity enhancement of PEDOT:PSS films via phosphoric acid treatment for flexible all-plastic solar cells. ACS Appl. Mater.
Interfaces 7, 14089-14094 (2015). https://doi.org/10.1021/ acsami.5b03309

41. X. Li, Y. Jiang, L. Shuai, L. Wang, L. Meng et al., Sulfonated copolymers with $\mathrm{SO}_{3} \mathrm{H}$ and $\mathrm{COOH}$ groups for the hydrolysis of polysaccharides. J. Mater. Chem. 22, 1283-1289 (2012). https://doi.org/10.1039/C1JM12954F

42. M. Carmo, T. Roepke, C. Roth, A.M. dos Santos, J.G. Poco et al., A novel electrocatalyst support with proton conductive properties for polymer electrolyte membrane fuel cell applications. J. Power Sources 191, 330-337 (2009). https://doi. org/10.1016/j.jpowsour.2009.01.086

43. C. Nguyen-Trung, D.A. Palmer, G.M. Begun, C. Peiffert, R.E. Mesmer, Aqueous uranyl complexes 1. Raman spectroscopic study of the hydrolysis of uranyl(VI) in solutions of trifluoromethanesulfonic acid and/or tetramethylammonium hydroxide at $25^{\circ} \mathrm{C}$ and $0.1 \mathrm{MPa}$. J. Solut. Chem. 29, 101-129 (2000). https://doi.org/10.1023/A:1005197030188

44. J.Y. Ouyang, C.-W. Chu, F.-C. Chen, Q. Xu, Y. Yang, Highconductivity poly(3,4-ethylenedioxythiophene):poly(styrene sulfonate) film and its application in polymer optoelectronic devices. Adv. Funct. Mater. 15, 203-208 (2005). https://doi. org/10.1002/adfm.200400016

45. S. Garreau, G. Louarn, J.P. Buisson, G. Froyer, S. Lefrant, In situ spectroelectrochemical Raman studies of poly(3,4ethylenedioxythiophene) (PEDT). Macromolecules 32, 68076812 (1999). https://doi.org/10.1021/ma9905674

46. J. Yuan, Y.Q. Zhang, L.Y. Zhou, G.C. Zhang, H.L. Yip et al., Single-junction organic solar cell with over $15 \%$ efficiency using fused-ring acceptor with electron-deficient core. Joule 3, 1140 (2019). https://doi.org/10.1016/j.joule.2019.01.004

47. J.W. Jung, W.H. Jo, Annealing-free high efficiency and large area polymer solar cells fabricated by a roller painting process. Adv. Funct. Mater. 20, 2355 (2010). https://doi.org/10.1002/ adfm.201000164 